African Journal of Biomedical Research, Vol. 10 (2007); 41 - 49

ISSN 1119 - 5096 (C) Ibadan Biomedical Communications Group

\title{
Full length Research Article \\ Management of Low Back Pain: - Attitudes and Treatment Preferences of Physiotherapists in Nigeria
}

OFIOAS

Full-text available at www.ajbrui.com www.bioline.br/md www.ajol.com

Received:

August, 2006

Accepted

(Revised):

November, 2006

Published

January, 2007

\author{
*Ayanniyi O, *Lasisi O.T, *Adegoke B.O.A, **Oni-Orisan \\ M.O \\ *Deparment of Physiotherapy, College of Medicine, University of \\ Ibadan, Nigeria \\ **Department Of Community Medicine, College of Health Sciences, \\ Lautech, Osogbo Campus, Osogbo, Nigeria.
}

\section{ABSTRACT}

Back Pain is one of the most frequent reasons for visiting a general practitioner or physical therapist. The objectives of this study were to investigate the attitudes and treatment preferences of Physiotherapists in Nigeria about the management of Low back Pain. A survey of 101 practicing physiotherapists from selected health institutions was carried out using a structured questionnaire. The results were analysed using descriptive and inferential statistics of Chi - square at 0. 05 . More than $90 \%$ of the physiotherapists surveyed recommended review of x-rays, and palpation methods, in the evaluation of patients, About $70 \%$ employed assessment of posture, McKenzie evaluation, Sacroiliac joint and neurological screening. The common treatment preferences by $83 \%$ of the physiotherapists surveyed was education regarding proper body mechanics in daily activities. More than $82.5 \%$ of the physiotherapists perceived McKenzie approach as very effective, while $60 \%$ rated it as most useful method in managing LBP. About 23\% of the subjects believed muscle strain and disc problem as the principal underlying causes of LBP among their patients. It was concluded that McKenzie approach was the most effective and useful method for managing LBP and education in proper body mechanics in daily activities was preferred in the management of LBP.

(Afr. J. Biomed. Res. 10: 41 - 49, January 2007)

Keywords: Attitudes, Preferences, Physiotherapists, Back pain management.

*Address for Correspondence: mckdalos@yahoo.com

Abstracted by:

African Index Medicus (WHO), CAB Abstracts, Index Copernicus, Global Health Abstracts, Asian Science Index, Index Veterinarius, Bioline international, African Journals online 


\section{INTRODUCTION}

Low back pain (LBP) is one of the most predominant of the numerous musculoskeletal disabling conditions (Cailliet, 1986) and one of the most common musculoskeletal disorders seen by health care practitioners all over the world (Jette and Davids, 1991).

According to Frymoyer and Cats-Baril (1991) most physiotherapists regularly face the challenge of caring for patients with low back pain symptoms with greater frequency as utilization for physiotherapy and other health care services for back problems increase.

It has been estimated that between one quarter and one half of patients treated by physiotherapists in acute care hospitals, private offices, and outpatient physiotherapy clinics suffer from LBP (Battie et al 1994 and Margo, 1994). Epidemiological reports indicated that seventy to eighty percent of people in Western Society have at least one episode of LBP in a lifetime (Biering-Sorensen, 1993). Nwuga (1993) reported that $88 \%$ of a group of Nigerian aged above 60years have had at least one episode of LBP in their lifetime. The wide spread incidence of LBP dysfunction and pain thus constitute a major public health crisis (Segal, 1983).

Recurrent episodes are a common feature of LBP (Apts, 1996), and up to 35\% of those with LBP develop a chronic problem (Taimela et al; 1997). This tendency for recurrence or chronicity in addition to poor responses of patients to treatment probably led to the development of many approaches in LBP management. These include diagnostic and treatment approaches of Mennel (1952), Maigne (1965), Cyriax (1980), McKenzie (1981), Maitland (1986) and Nwuga (1990). In the recent past a number of researchers, Battie et al; (1994), Gracey et al (1997) and Foster et al, 1999) have conducted studies among physiotherapists in the United States of America, Britain and Ireland to ascertain the physiotherapists; approaches that is attitudes and treatment preferences among physiotherapists to the management of LBP.

However, to date no such studies have been conducted in Nigeria. In line with this emerging world-wide trend the present study was conceived to find out the attitudes and treatment preferences of physiotherapists practicing in Nigeria to the management of LBP.

\section{MATERIALS AND METHODS}

\section{Materials}

The questionnaire for this study was adopted from the work of Battie et al (1994) and the study was patterned after a similar study carried out by the same authors among physical therapists in Washington, U.S.A. The questionnaire was slightly re-arranged such that questions 16 to 20 seeking demographic information were brought forward while the numbering of the remaining questions were readjusted accordingly. However, the structure and content of the questionnaire remained unchanged in order to ensure its face and content validity.

\section{Questionnaire Design}

The questionnaire consisted of 20 open and close-ended questions. Question 1 to 5 sought demographic information, questions 6 to 8 sought data on physiotherapists evaluation, treatment preferences and confidence in treating patients with back pain. Question 9 consisted of a series of statements concerning physiotherapists beliefs about patients with LBP and the use of the placebo effect.

Question 10 sought information on the effectiveness of several approaches to LBP, including the approaches such as Cyriax, McKenzie, Myofascial release and other approaches specified by the physiotherapists. Question 11 sought information about attitudes of Physiotherapists toward various approaches to low back pain management while question 12 sought information on attitudes of physiotherapists about low back pain and question 13 focused on physiotherapist beliefs about the causes of back symptoms. Question 14 sought information on types of low back pain, while question 15 focused on duration of treatment given by physiotherapists and question 16 sought information on how many times 
physiotherapists see a patients for an episode of back pain.

Question 17 and 18 sought information on how well prepared physiotherapists are to manage low back pain, while question 19 sought information on attitudes of doctors toward physiotherapists concerning referral systems and question 20 sought to know if the physiotherapists ever had low back pain: According to (Battie et al, 1994) the list of options was developed with assistance from a group of clinically active physical therapists from several practice settings.

\section{Subjects}

Subjects for this study were qualified practicing physiotherapists drawn from the selected health facilities [secondary and tertiary health institutions as well as private physiotherapy Clinics]. Subjects for this study were recruited from Lagos state, Kano state, Ogun state, Oyo state and Enugu state.

The inclusion criteria for the participants are: [1] The participants must be practicing in Nigeria

[2] Must have a minimum of 3 years experience and above.

Exclusion criteria are:

[1] Itinerant Physiotherapists

[2] Retired Physiotherapists

[3] Non practicing Physiotherapists.

\section{Method}

\section{Sampling Techniques}

Participants for this study were recruited from all identified health facilities in Nigeria. A purposive sampling technique was utilized in recruiting the participants for the study.

\section{Research Design}

The research design for this study was a crosssectional survey.

\section{Procedure}

Permission for the distribution of the study questionnaire in the selected physiotherapy facilities was obtained from the Chief Physiotherapist/head of department. There after, individual consent of the concerned physiotherapists was sought and obtained. The purpose of the study was explained to the intended participants in this study through a letter of transmitter attached to each copy of the questionnaire.

The questionnaire was distributed to the physiotherapists in the selected facilities either by hand or by surface mail through a contact person in such facilities. Subsequently, after three weeks, reminder letters were sent out to all the participants while some were contacted by telephone. This was done to encourage prompt response to the questionnaire and ensure early return of same.

\section{Data Analysis}

Descriptive statistics of range, mean and standard deviation were computed for age of the subjects, years in practice, length of initial low back pain visit (minutes), length of follow up low back pain consultation (minutes) and number of visits for LBP treatment consultation, while percentages were computed for evaluation preferences and treatment preferences of physiotherapists for the three hypothetical patients.

Chi-square tests were carried out to determine if there were relationship present in practice styles, attitudes and treatment preferences about LBP.

\section{RESULTS}

The demographic data of the subjects are shown in table 1 . The mean age of the subjects was 35.7 \pm 7.1 years, while the mean year of experience in practice was $10.1 \pm 6.5$ years. A total of 101 (54 males and 47 females) Physiotherapists participated in this study. The majority of the participants (63.4\%) came from tertiary health institutions (THI). 25.7\% came from secondary health institutions (SHI) while the remaining (10.9\%) were from private physiotherapy Clinics. The hospital setting in which LBP patients were seen by participants were hospital out patient department 33.2\%, hospital inpatient department $31.6 \%$ while $17.6 \%$ of the participants indicated that they attended to the low back pain patients in the private practice 
Clinic and patients home respectively. Analysis of the participants work load per week indicated that LBP patients constituted $27 \%$ of the total work load.

Table 2 and 3 shows the evaluation and treatment preferences for the three hypothetical LBP patients of the participants. About $90 \%$ of the physiotherapists who participated in this study indicated that they usually employed palpation method to evaluate the three hypothetical LBP patients, while more than three quarter of the participants indicated review of $\mathrm{x}$ ray, evaluation of the functional activity and range of motion method in their evaluations of all the three hypothetical patients. More than three quarters of the physiotherapists who participated in this study indicated that they usually employed postural method of eamination in their evaluations of the chronic and acute recurrent LBP patients while about $75 \%$ of the participants indicated sacroiliac joint screening method in their evaluation of the chronic and acute nonrecurrent LBP patients.

The common treatment preferences of the physiotherapists who participated in this study for the three hypothetical LBP patients was education regarding proper body mechanics in daily activities. About $71 \%$ of the participants recommended ice modality in the treatment of acute-non recurrent LBP patients, while more than $50 \%$ of the physiotherapists who participated in this study recommended TENS for the treatment of the three hypothetical LBP patients. More than $55 \%$ of the participants indicated heat modality for the treatment of chronic and acute recurrent LBP patients.

Table 4 shows the effectiveness and usefulness of the various approaches in managing LBP patients. Eighty three percent of physiotherapists who participated in this study perceived McKenzie approach as very effective, while 60\% rated it as the most useful approach in managing low back pain. About $60 \%$ of the physiotherapists indicated Nwugarian approach as very effective, while $27 \%$ perceived it as most useful approach in managing LBP patients.

Disc diseases and muscle strain were indicated to account for the greatest proportion of back pain symptoms. Twenty four percent of the physiotherapists surveyed believed that disc disease was the underlying cause of the back pain symptoms of their patients this was followed by $23 \%$ who believed that muscle strain was the underlying cause of LBP of their patients.

Table 1:

Provider and practice characteristics

\begin{tabular}{lccc}
\hline Characteristics & X & SD & Range \\
\hline & & & \\
Age (in years) & 35.7 & 7.1 & $24-58$ \\
Years in practice & 10.1 & 6.5 & $3-28$ \\
Mean length of initial LBP visit (Mins) & 65.6 & 19.9 & $30-120$ \\
Mean length of follow up LBP visit (Mins) & 39.6 & 11.5 & $15-70$ \\
Mean number of visits for LBP treatment & 9.0 & 4.4 & $3-20$ \\
Percentage of patients with LBP per week among all patients & 27 & & $1-60$ \\
seen. & 52 & & $10-96$ \\
Percentage of patients with chronic LBP Symptoms & 26 & & $2-70$ \\
Percentage of patients with acute recurrent LBP & 22 & & $0-80$ \\
Percentage of patients with acute non Recurrent LBP & & & \\
\hline
\end{tabular}

KEYS: $\mathrm{X}=\quad$ Means; $\mathrm{SD}=$ Standard deviation; Mins=Minutes 
Table 2:

Evaluation preferences of physiotherapists for the three hypothetical patient.

\begin{tabular}{lccc}
\hline \multicolumn{1}{c}{$\begin{array}{c}\text { Evaluation } \\
\text { Recurrent LBP }\end{array}$} & $\begin{array}{c}\text { Chronic LBP } \\
\text { (Patient 1) } \\
\%\end{array}$ & $\begin{array}{c}\text { Acute recurrent LBP } \\
\text { patients (2) } \\
\%\end{array}$ & $\begin{array}{c}\text { Acute-non } \\
\text { Recurrent LBP } \\
\text { patient (3) } \\
\%\end{array}$ \\
\hline McKenzie evaluation & 71.3 & 75.3 & 63.4 \\
Palpation & 90.1 & 89.1 & 90.1 \\
Range of movement & 88.1 & 78.2 & 85.2 \\
Sacroiliac joint screening & 83.2 & 67.3 & 72.3 \\
Neurological screening & 62.4 & 64.4 & 72.3 \\
Posture & 81.2 & 79.2 & 64.4 \\
Joint accessory movement. & 53.5 & 41.6 & 49.5 \\
LE quadrant screening & 12.9 & 19.8 & 16.8 \\
Functional activity evaluation & 80.0 & 78.2 & 74.2 \\
Review of x-rays & 90.1 & 81.2 & 8.9 \\
Other (specify) & 14.9 & 12.9 & \\
\hline
\end{tabular}

KEY: LBP=Low back pain; \%= Percentage; LE=Lower extremity

Table 3:

Treatment preferences of physiotherapists for three hypothetical patients (in percentages)

\begin{tabular}{lccc}
\hline \multicolumn{1}{c}{ Treatment recurrent LBP } & $\begin{array}{c}\text { Chronic LBP (Patient } \\
\text { 1) }\end{array}$ & $\begin{array}{c}\text { Acute recurrent LBP } \\
\text { (Patient 2) }\end{array}$ & $\begin{array}{c}\text { Acute-non } \\
\text { (Patients 3) }\end{array}$ \\
\hline Bed rest & $\%$ & $\%$ & $\%$ \\
Heat & 18.8 & 22.8 & 60.4 \\
Ice & 56.4 & 64.4 & 18.8 \\
Ultrasound & 30.7 & 16.8 & 71.3 \\
Tens & 25.7 & 25.7 & 19.8 \\
Analgesics & 52.5 & 58.4 & 51.5 \\
Anti-inflammatory & 34.7 & 34.7 & 41.6 \\
Education regarding & 10.9 & 9.9 & 26.7 \\
Proper body mechanics in daily activities & 86.1 & 77.2 & 67.3 \\
Aerobic exercises & & & \\
Stretching exercises & 10.99 & 20.8 & 15.8 \\
Strengthening exercises & 35.6 & 54.5 & 17.8 \\
Spinal mobilization & 40.6 & 48.5 & 24.8 \\
Traction & 48.5 & 55.4 & 33.7 \\
Others (specify) & 24.8 & 25.7 & 29.7 \\
\hline KEY: TENS & 11.9 & 11.9 & 9.9 \\
\hline
\end{tabular}

KEY: TENS $\quad=\quad$ Transcutaneous electrical nerve stimulation

Table 4:

Effectiveness of Evaluation and Treatment preferences

\begin{tabular}{|l|l|l|l|l|l|}
\hline Approach & $\begin{array}{l}\text { Very Effective } \\
(\mathbf{\% )}\end{array}$ & $\begin{array}{l}\text { Moderately } \\
\text { Effective (\%) }\end{array}$ & $\begin{array}{l}\text { Somewhat } \\
\text { Effective (\%) }\end{array}$ & Not $\begin{array}{l}\text { Effective } \\
\mathbf{( \% )}\end{array}$ & $\begin{array}{l}\text { Dont Know } \\
\mathbf{( \% )}\end{array}$ \\
\hline Cyriax & 9.9 & 29.7 & 15.8 & 0 & 45.6 \\
\hline Mckenzie & 82.5 & 14.2 & 4.3 & 0 & 0 \\
\hline Myofascial & 21.1 & 42.2 & 16.6 & 0 & 21.1 \\
\hline Others & 59.9 & 3.7 & 26.2 & 11.2 & 0 \\
\hline
\end{tabular}


Table 5 shows the comparison of the responses of physiotherapists who worked solely in tertiary health institutions (n-64), secondary health institutions (n-26) and private physiotherapists Clinic $(n=11)$.

Table 6 shows comparison of effectiveness of the approaches among physiotherapists practicing in THI, SHI and PPC for the three hypothetical patients. There was significant difference in the number of physiotherapists practicing in PPC that perceived Cyriax approach's effectiveness when compared with THI and SHI $\mathrm{P}<0.000$.

Also there was significant difference in the number of physiotherapists practicing in SHI that perceived McKenzie approach's effectiveness when compared with THI and PPC $\mathrm{P}<0.000$. Likewise when compared PPC with SHI and THI $\mathrm{P}<0.000$ for the myofascial release effectiveness.

Table 7 shows comparison of usefulness of the approaches among Physiotherapists practicing in THI, SHI and PPC for the three hypothetical patients. There was significant difference in number of physiotherapists practicing in PPC that perceived McKenzie approach's usefulness when compared with THI and SHI $\mathrm{P}<0.000$. And there was no significant difference in the number of physiotherapists practicing in THI, SHI and PPC that perceived Cyriax approach's usefulness $\mathrm{P}<0.779$, likewise when compared with myofascial release approach's usefulness among physiotherapists practicing in THI, SHI and PPC $\mathrm{P}<0.449$.

Majority of the $(63.6 \%)$ physiotherapists surveyed from PPC were well prepared at entrance to physiotherapy practice when compared to $60.9 \%$ and $61.5 \%$ of those who were in THI and SHI respectively $(\mathrm{P}<0.05)$ as shown in Table 8 . After years of practice $72 \%$ of the physiotherapists from PPC were very well prepared and there is a great improvement on the part of the physiotherapists surveyed from the SHI $65.4 \%$ are very well prepared $\mathrm{P}<0.05$ as shown in Table 9.

\section{Table 5:}

Comparison of provider and Practice characteristics among practice setting. Values are presented as Mean

\begin{tabular}{lccc}
\hline & THI & SHI & PPC \\
\hline Mean age (years) & 34.2 & 36.3 & 30.00 \\
Mean no. of yrs in practice & 28.2 & 8.8 & 6.0 \\
Means no. of outpatient visit per week & 31.5 & 26.8 & 20.9 \\
Mean no. of patient with LBP per week among all patients & 9.3 & 8.2 & 5.7 \\
Mean length of initial visits (mins) & 54.5 & 52.9 & 50.00 \\
Mean no. of visit for patient & 8.1 & 8.6 & 11.4 \\
Mean no. of acute non-recurrent LBP & 21.6 & 19.00 & 35.5 \\
Mean no of acute recurrent LBP & 33.6 & 47.8 & 35.5 \\
Mean no of chronic LBP & 52.0 & 47.8 & 36.4 \\
\hline
\end{tabular}

KEYS: $Y$ = Years; $L B P=$ Low back pain; $T H I=$ Tertiary health institution; $S H I=$ Secondary health institution; $P P C=$ Private physiotherapy clinic

Table 6:

Comparison of Effectiveness of the approaches among practice setting for three hypothetical patients

\begin{tabular}{lllllll}
\hline Approach & THI & SHI & PPC & $\mathbf{X}^{\mathbf{2}}$ & P-value & Comments \\
& $\mathbf{N = 6 4}$ & $\mathbf{N = 2 6}$ & $\mathbf{N - 1 1}$ & & & \\
\hline Cyriax & 47.3 & 31.1 & $73.5^{*}$ & 21.04 & 0.000 & Significant \\
Mckenzie & 91.5 & $77.7^{*}$ & $91.8^{*}$ & 33.85 & 0.000 & Significant \\
Myofacial & 61.6 & 62.2 & 91.8 & 21.63 & 0.000 & Significant \\
Others & 34.7 & $19.4^{*}$ & 36.7 & 19.81 & 0.000 & Significant
\end{tabular}

Significant at 0.05 level $; \mathrm{X}^{2}=$ Chi-square ; THI = Tertiary health institution; SHI =Secondary health institution 
Table 7:

Comparison of Usefulness of the approaches among practice setting for three hypothetical patient

\begin{tabular}{llllccl}
\hline Approach & THI & SHI & PPC & $\mathbf{X}^{\mathbf{2}}$ & P-value & Comments \\
& $\mathbf{N = 6 4}$ & $\mathbf{N = 2 6}$ & $\mathbf{N}-\mathbf{1 1}$ & & & \\
\hline Cyriax & 16 & 3.9 & 18.4 & 0.5 & 0.779 & Not Significant \\
Mckenzie & 77.3 & $89.2^{*}$ & 64.3 & 32.28 & 0.000 & Significant \\
Myofacial & 4.7 & 3.9 & 9.2 & 1.6 & 0.449 & Not Significant \\
Others & $15.8^{*}$ & 3.9 & 9.4 & 13.5 & 0.001 & Significant \\
\hline
\end{tabular}

Significant at 0.05 level $; \mathrm{X}^{2}=$ Chi-square $; \mathrm{THI}=$ Tertiary health institution; $\mathrm{SHI}=$ Secondary health institution

Table 8:

Comparison of the preparedness after Qualification among practice setting

\begin{tabular}{lllllll}
\hline Preparedness & THI & SHI & PPC & $\mathbf{X}^{\mathbf{2}}$ & P-value & Comments \\
& $\mathbf{N}=\mathbf{6 4}$ & $\mathbf{N = 2 6}$ & $\mathbf{N - 1 1}$ & & & \\
\hline Very well & 6.3 & 3.9 & 0 & 3.0 & 0.223 & Not Significant \\
Well & 11.1 & 27.2 & $64.2^{*}$ & 0 & 1.000 & Not Significant \\
Adequate & 61.1 & 62.2 & $27.62^{*}$ & 36.73 & 0.000 & Significant \\
Poorly & $18.9 *$ & 7.8 & 9.2 & 14.8 & 0.001 & Significant \\
Very Poor & 1.6 & 0 & 0 & 0.33 & 0.564 & Not Significant \\
\hline Significant at 0.05 level $; \mathrm{X}^{2}$ & = Chi-square $;$ THI = Tertiary health institution; SHI =Secondary health institution
\end{tabular}

Table 9:

Comparison of the preparedness after year of Experience among practice settings.

\begin{tabular}{|c|c|c|c|c|c|c|}
\hline Preparedness & $\begin{array}{l}\text { THI } \\
\mathbf{N}=64\end{array}$ & $\begin{array}{c}\text { SHI } \\
\mathrm{N}=26\end{array}$ & $\begin{array}{l}\text { PPC } \\
\text { N-11 } \\
\end{array}$ & $\mathrm{X}^{2}$ & P-value & Comments \\
\hline Very well & $39.5^{*}$ & 66.0 & 73.5 & 8.68 & 0.013 & Significant \\
\hline Well & 45.8 & 35 & 9.9 & 32.0 & 0.000 & Significant \\
\hline Adequate & 7.9 & 0 & 9.1 & 1.29 & 0.257 & Not Significant \\
\hline Poorly & 6.3 & 0 & 0 & 0.67 & 0.414 & Not Significant \\
\hline Very Poor & 0 & 0 & 0 & 0 & & \\
\hline
\end{tabular}

\section{DISCUSSION}

Low back pain (LBP) is one of the most common ailments seen by many physiotherapists. It has been estimated that between one quarter and one half of patients treated by physiotherapists suffer from LBP (Battie et al, 1994 and Margo, 1994). The findings of this study support the above statement with LBP estimated to account for $27 \%$ of total patients seen by the physiotherapists who participated in this study.

The result of this study is also in agreement with that of Lambers (1991), Van der velden et al (1992) Dekker and Van Barg (1995) and Van Tulder et al (1996) who stated that back pain is one of the most frequent reasons for visiting a general practitioner or physiotherapists. Similarly, Kersen and Groenew egen (1990) also reported that in Netherlands, 22\% of patients referred by general practitioner for physical therapy have back pain. It was also reported by Jette et al (1994) that in United States, patients with low back pain represent $25 \%$ of all outpatients discharged from physical therapy practice. These similarities indicate that back pain is a universal problem.

The finding from this study showed that twenty-four percent of the physiotherapists believed in disc problems as the principal underlying cause of low back pain. This is in agreement with the McKenzie approach, which is based on the theory that changes in the disc induced by mechanical stresses are responsible for the onset of low back symptoms (Battie et al, 1994). Belief in disc disease as cause of LBP was closely followed by belief in muscle strains as 
cause of BP (23\%). The belief in the muscular strains as the principal underlying cause of low back pain is in agreement with the finding of Cherkin and co-workers (1992) which reported that family physicians rated muscle strain as the leading cause of back pain. Spinal arthritis was also identified as one of the underlying causes of LBP by $17.8 \%$ of the practitioners.

Although physiotherapists employed a variety of treatment modalities and evaluation, the McKenzie method was said to be the most popular approach for managing patients with back pain, it was also perceived as very effective and rated as most useful method. This is in agreement with work of Battie et al (1994) and this showed that McKenzie approach is world wide accepted for managing LBP. Education in proper body mechanics for activities of daily living and the use of transcutaneus electrical nerve stimulation (TENS) were among the most common treatment preferences. This finding is in agreement with the views of Battie et al, (1994), Gracey et al, (1997) and Foster et al, (1999) which indicated McKenzie's approach; Maitland's mobilization as well as education regarding proper body mechanics in daily activity as most popular treatment used for the management of LBP. For patients with chronic and acute recurrent symptoms, physiotherapists involved in this study favoured heat modality as well as spinal mobilization and were less inclined to recommend bed rest. However, for patients with acute LBP and sciatica physiotherapists recommended ice treatment as well as bed rest. Some Physiotherapists favour another treatment approach (Nwugarian) and perceived it as very effective and rated it as one of the useful methods. Myofascial release was also perceived as moderately effective technique. Strengthening exercise as well as stretching exercise was preferred by physiotherapists for patients with chronic and acute recurrent LBP.

In evaluation of patients with the three hypothetical LBP, the most frequently employed methods were palpation, range of motion, McKenzie evaluation, posture and Sacroiliac joint screening. Most of the physiotherapists participating in this study (70\%) were confident that they could affect the rate of recovery of the three hypothetical patients positively.

\section{Conclusion / Clinical Implications}

Many studies have confirmed the benefits of physiotherapy treatment for the patients with low back pain. A number of researchers (Battie et al, 1994; Gracey et al, 1997 and Foster et al, 1999) have conducted studies among physiotherapists in the United States of America, Britain and Ireland and confirmed the popularity of McKenzie's approaches, Maitland mobilization and education regarding proper body mechanics in daily activities among physiotherapists.

The findings of this study are applicable to current clinical practice and the significance of the treatment preferences could have resulted from the nature of training and years of experience.

Based on the outcome of this study, the following conclusions were made

1. McKenzie approach was perceived as the most effective and useful method for the management of LBP.

2. Education regarding proper body mechanics in daily activity was the common treatment preferences for the management of LBP.

3. Ice modality and bed rest were recommended for acute LBP and sciatica.

4. Heat and TENS modalities were recommended for chronic and acute recurrent LBP.

5. Palpation method and review of $\mathrm{x}$-ray were the common methods of evaluating LBP. Other methods are functional activity and range of motion.

\section{REFERENCES}

Apts DW. (1996); Back injuries prevention Handbook. Levis publishers, Chelsea, U.S.A; 88-96.

Battie, M.C; Cherkin D.C, Dunn. R; CIDL M.A. ands Wheeler K.J. (1994). Managing low back pain. Attitudes and treatment preferences of physical therapists. Physical therapy 74 (3). 219226.

Biering-Sorensen F.A (1983); prospective study of low bank pain patients in a general population: 1 . Occurrence, recurrence and aetiology. Scandinavian Journal of Rehabilitation Medicine. 15, 71-79. 
Cailliet R. (1986); Soft tissue pain and disability. F.A. Davis Company, Philadelphia 4.

Cherkin, D.C; Deyo, R.A Volinnm, E; Lowser, J.D (1992). Use of the International Classification of Diseases (ICD 9-cm) to identify hospitalization for mechanical low back problems in administration databases. Spine 17:817-825.

Cyriax J. (1980); Textbook of Orthopaedic medicines. Vol. $15^{\text {th }}$ ed. Balliere Tindall, London.

Dekker .J; Van Baar M.E; Curfs E.C; Kersens J.J. (1993). Diagnosis and treatment in Physical therapy: An investigation of their relationship, physical therapy: 73:568-580.

Foster N. E, Thompson K. A. Baxter G. D. Allen J. M. (1999). Management of non specific low back pain by physiotherapists in Britain and Ireland. A descriptive questionnaire of current clinical practice Spine. 24 (13): 1332-42.

Frymoyer J.W; (1988). Back pain and Sciatica. New England Journal of Medicine 18:291-300.

Frymoyer J.W; Cats-Baril W.I. (1991). An Overview of the incidences and costs of Lowback pain, Orthopaedic Clinics of North America: 22:263-271.

Jette A.M. and Davids KD. (1991); A comparison of hospital-hospital based and private outpatient physical therapy practices. Physical Therapy. 74, 366-375.

Jette A.M; Smith K, Haleg S.M; Davis K.D., (1994). Physical therapy episodes of case of patients with low back pain, Physical therapy. 74:101-110.

Kersens J.J, Greone Wegen P.P (1990). Referrals to physiotherapy: The relation between the number of referrals, the indication for referral, and the inclination to refer Social Science and Medicine, 30:797-804.

Maigne R., (1965); The concept of painlessness and opposite motion in spinal manipulations. American Journal of physical medicine. 44:55-59.
Maitland GD. (1986); Vertebral Manipulation $5^{\text {th }}$ edition Butterworths.

Margo K, (1994). Diagnosis, treatment and prognosis in patient with low back pain. America Family Physician 49 (1) 171-179.

McKenzie RA. (1981) The lumbar spine; Mechanical diagnosis and therapy. Spinal publication, Walkanae, New Zealand.

Mennell J. (1952); The Science and Act Joint Manipulation. Vol. London Churchill and A. Ltd. 1214.

Nwuga VCB, (1990); Manual Treatment of Back pain. Shameson C.I. Ltd, Nigeria.

Nwuga VCB. (1993); Old age and low back pain among Nigerians. Health Team. 1:6-8. 311-317.

Segal, D.D. (1983). An anatomic and biomechanic approach to low back health. A preventive approach. Journal of sports medicine and physical fitness. 23(4). 411-421.

Taimela S, Kujala UM, Salminem JJ and Viljanen T. (1997); The prevalence of low back pain among children and adolescents: A nationwide, cohort-based questionnaire survey in Finland. Spine. 22, 11321136.

Van der velden J. De Bakker D.H; Claessens A.A.M.C; Schellevis F.G; (1992). Morbidity in General Practice, Dutch National Survey of General Practice, Utrecht, the Netherlands, Netherlands Institute for primary health care. 79 (3).

Van Tulder M. (1996). Diagnostics and Treatment of chronic low back pain in primary care. Amsterdam, the Netherlands: Thesis publisher. 